\title{
Applying policy and health effects of air pollution in South Korea: focus on ambient air quality standards
}

\author{
Jongsik Ha \\ Korea Environment Institute, Seoul, Korea
}

\begin{abstract}
Objectives South Korea's air quality standards are insufficient in terms of establishing a procedure for their management. The current system lacks a proper decision-making process and prior evidence is not considered. The purpose of this study is to propose a measure for establishing atmospheric environmental standards in South Korea that will take into consideration the health of its residents.

Methods In this paper, the National Ambient Air Quality Standards (NAAQS) of the US was examined in order to suggest ways, which consider health effects, to establish air quality standards in South Korea. Up-to-date research on the health effects of air pollution was then reviewed, and tools were proposed to utilize the key results. This was done in an effort to ensure the reliability of the standards with regard to public health.

Results This study showed that scientific research on the health effects of air pollution and the methodology used in the research have contributed significantly to establishing air quality standards. However, as the standards are legally binding, the procedure should take into account the effects on other sectors. Realistically speaking, it is impossible to establish standards that protect an entire population from air pollution. Instead, it is necessary to find a balance between what should be done and what can be done.

Conclusions Therefore, establishing air quality standards should be done as part of an evidence-based policy that identifies the health effects of air pollution and takes into consideration political, economic, and social contexts.
\end{abstract}

Keywords Evidence-based policy, Health effects, National Ambient Air Quality Standards

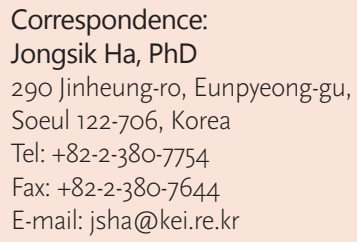

Correspondence: Jongsik $\mathrm{Ha}$, PhD

290 Jinheung-ro, Eunpyeong-gu,

Soeul 122-706, Korea

Tel: $+82-2-380-7754$

Fax: $+82-2-380-7644$

E-mail: jsha@kei.re.kr

Received: July 15, 2014

Accepted: August 12, 2014

Published online: October 1, 2014

This article is available from: http://e-eht.org/

\section{Introduction}

A wide range of factors exist that can pose health risks to local communities. Among these, the health burden on local communities because of environmental risks contributes to $24 \%$ (21\%-27\%) of the total disease burden and $23 \%(21 \%-25 \%)$ of the total deaths [1]. Furthermore, a recent report from the International Agency for Research on Cancer stresses that the mixtures that comprise air pollution —an environmental riskare carcinogenic to humans [2]; the World Health Organization reports that outdoor air pollution was responsible for the deaths of 3.7 million people worldwide in 2012 [3]. In South Korea, approximately 1,246 people (or 428-2,059) from the Seoul metropolitan region are estimated to have died from short-term exposure to particulate matter less than or equal to $10 \mu \mathrm{m}$ in diameter $\left(\mathrm{PM}_{10}\right)$ in 2010 [4].

On a related note, health effects due to environmental risks are characterized by complex, mutual interactions among the health risk factors and their effects, as well as low exposure levels and relatively long latency periods [5]. As a result, few are aware of the dangers of environmental risk factors, despite the fact that exposure to them contributes considerably to disease prevalence and mortality rates in local communities. In any case, as environmental risks have involuntary effects on the health of 
entire populations of local communities, they should be managed at a national level as a supportive measure for the health care of each individual.

Generally, the effect of environmental factors on health and policy-making can be explained through the Driving Force-Pressure-State-Exposure-Effect-Action (DPSEEA) model [6]. Ideal policy-making, in terms of environmental health, involves a reduction of environmental risk exposure, as well as the risks themselves, in every stage of the process (Figure 1). However, according to the DPSEEA model, accurate policy-based intervention is not that simple, as the time lag between the reduction of exposure to environmental risk factors and its effect on disease prevalence, as well as other variables that affect biological health, make the intervention difficult to implement [7].

With regard to the DPSSEA model in particular, national policy-based intervention for air pollution is closely related to the establishment of air quality standards, as the setting-up of those standards can lead to managing sources of pollution while reducing pollutant concentrations and relevant health risk factors, and ultimately ensuring healthy living in local communities $[8,9]$. Moreover, air quality standards have the strongest legal bearing in court, as all atmosphere-related policies, including those pertaining to environmental health, may be considered to be methods for reducing exposure and meeting the standards.

In summary, the establishment of air quality standards, in terms of atmosphere-related policies, functions as the foundation on which other policies may be established and given immense funding, because the standards must be met. Consequently, before atmosphere-related policies can be established and implemented, there must be a clear demonstration to the people of a nation that adherence to air quality standards will minimize the environmental risks to their health. Thus, when dealing with atmosphere-related policies, it is important to ensure that atmospheric environmental standards are reliable.

There are several ambiguous points as to how South Korea's current atmospheric environmental standards came to be established and maintained. There are no records of the decisionmaking processes that were served as the basis for establishing the current standards. Furthermore, the environmental background (at the time when the standards were established) and the backgrounds of the specialists who contributed to the establishment, as well as the limitations of the chosen standards and any consequent revisions to them, remain unknown. In contrast, air quality standards in the US are created by considering a diverse array of perspectives, systematic procedures, and scientific evidence, as well as discussions among stakeholders [7].

The purpose of the current study is to investigate and summarize the system and procedures involved in establishing general air quality standards in the US, with the goal of proposing a measure for establishing atmospheric environmental standards

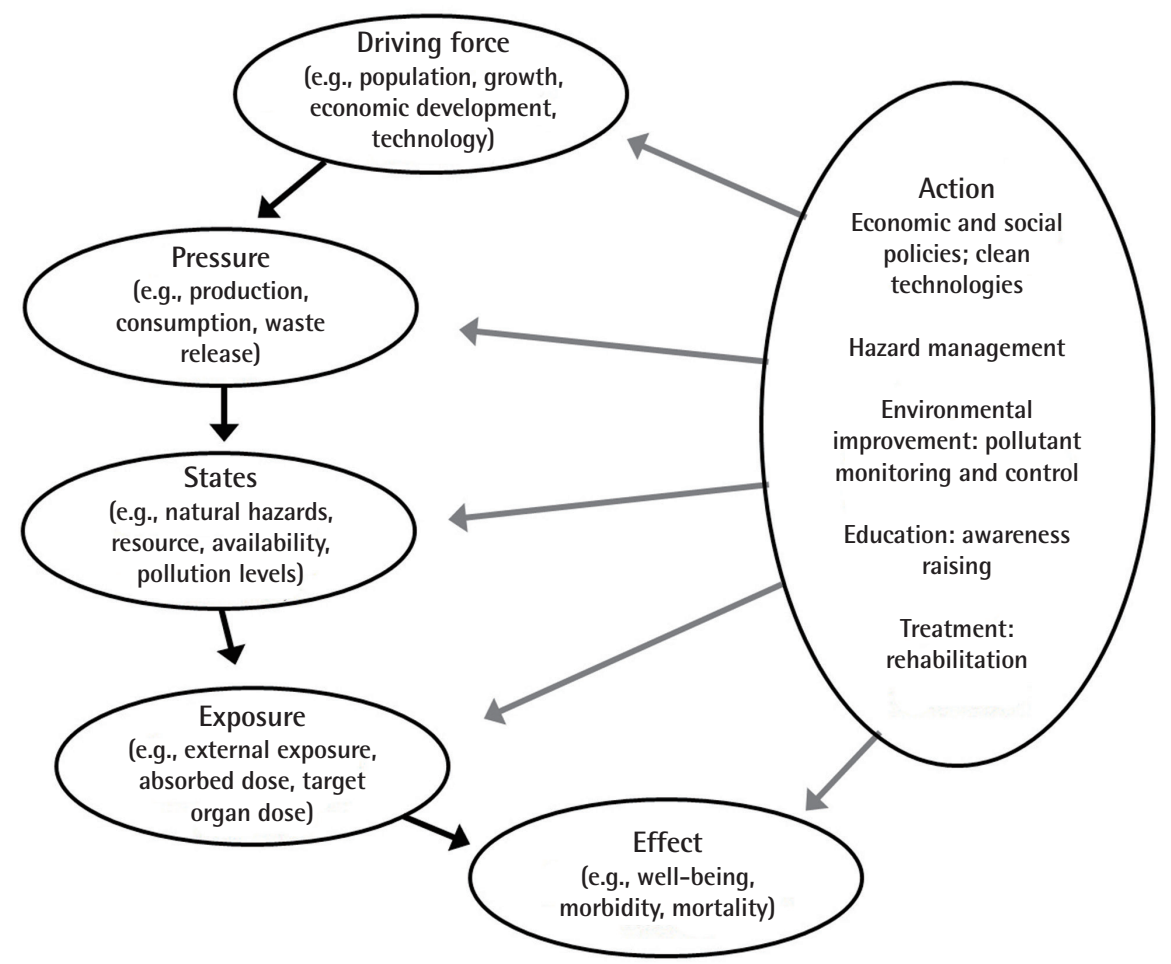

Figure 1. The Driving Force-Pressure-State-Exposure-Effect-Action framework. Modified from Corvalán C, et al. Decision-making in environmental health: from evidence to action [6]. 
in South Korea that will take into consideration the health of its residents. Furthermore, the current study will present research developments in which the effects of air pollution on health are evaluated, as well as tools that can utilize and apply these findings, for the purpose of implementing the standards nationally.

\section{Materials and Methods}

To investigate and summarize the system and procedures involved in establishing general air quality standards in the US, the step-by-step process, purpose, and characteristics of the National Ambient Air Quality Standards (NAAQS), as proposed by the Environmental Protection Agency (EPA), were examined. Afterward, the methodology regarding the effects of environmental risks on public health was summarized in detail. Based on these findings, future directions for establishing atmospheric environmental standards in South Korea were suggested.

To find reliable tools for establishing atmospheric environmental standards that take into consideration public health, studies pertaining to South Korea in the Science Citation Index (SCI) of the Health Effects Institute (HEI)'s Public Health and Air Pollution in Asia (PAPA) project were selected and analyzed. With regard to the tools to utilize and apply the findings of these studies in real life, those that may be useful in linking scientific evidence to environmental health policies were sum- marized.

\section{Results and Discussion}

\section{Establishment of National Ambient Air Quality Standards}

In accordance with the US Clean Air Act, the US EPA requires that scientific information and standards concerning common air pollutants - namely $\mathrm{PM}, \mathrm{O}_{3}, \mathrm{NO}_{2}, \mathrm{SO}_{2}, \mathrm{~Pb}$, and $\mathrm{CO}$ - be examined every five years, and NAAQS must undergo primary and secondary reviews. The standard for the primary review is the adequate margin of safety, which concerns personal health, while the standard for the secondary review is based on human welfare from known or predicted adverse effects. Human welfare is affected by soil, water quality, cultivation, vegetation, man-made materials, animals, weather, and visibility, etc.

The reviewing process for NAAQS consists of five stages: the Integrated Review Plan (IRP), the Integrated Science Assessment (ISA), the Risk/Exposure Assessment (REA), the Policy Assessment (PA), and Rulemaking (Figure 2). The Clean Air Scientific Advisory Committee (CASAC) has been established and maintained for the purpose of reviewing the scientific data and standards for each air pollutant during each of these processes.

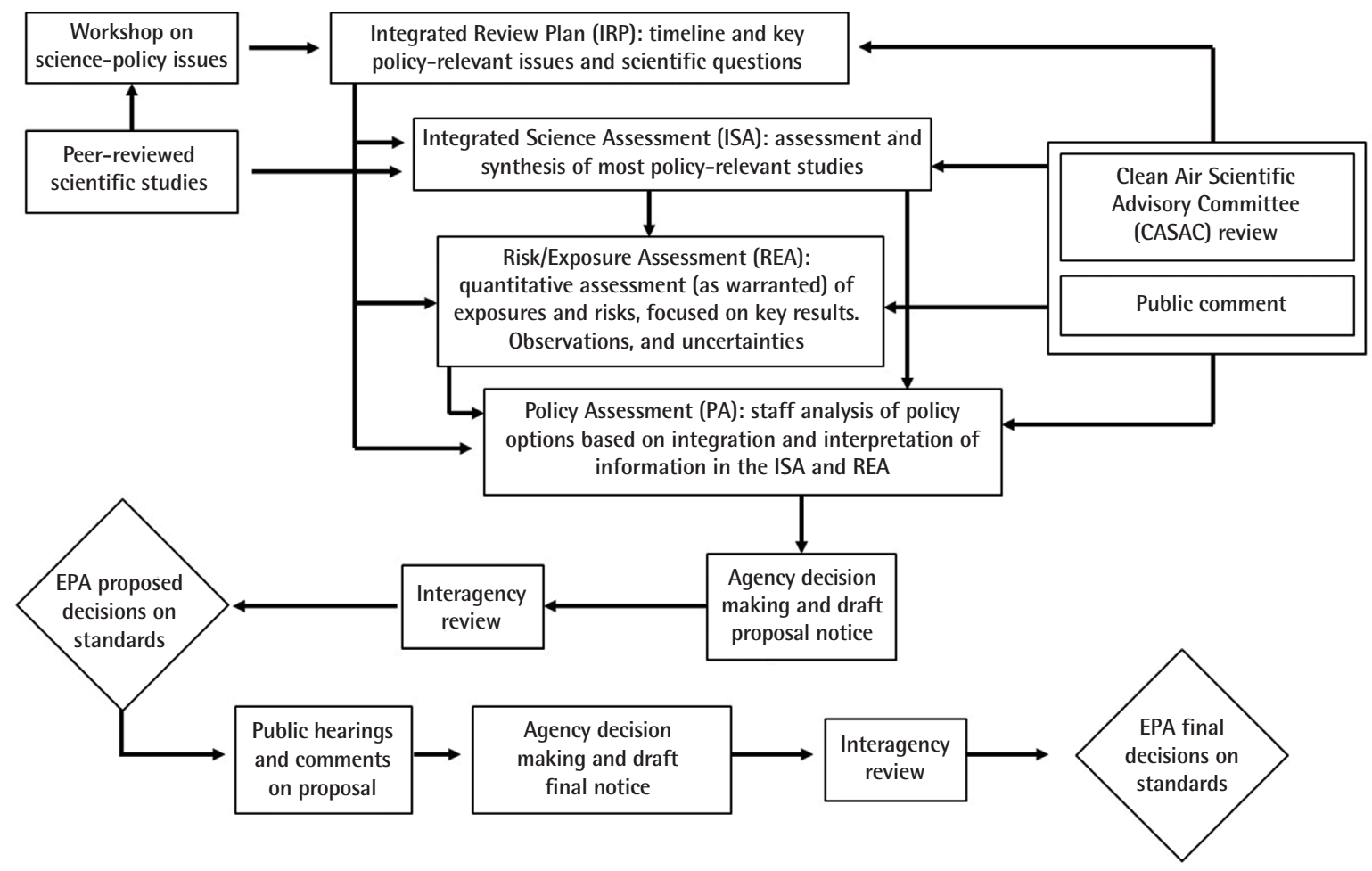

Figure 2. National Ambient Air Quality Standards (NAAQS) review process. Modified from Environmental Protection Agency. Integrated review plan for the ozone national ambient air quality standards [8]. EPA, Environmental Protection Agency. 
CASAC provides scientific reviews regarding the results (reports from each stage, etc.) of the 12-15 meetings held each year for each stage of NAAQS. CASAC's role includes 1) reviewing the primary and secondary air quality standards and suggesting appropriate revisions to the administrator, 2) advising the administrator with regard to the relatively positive impact of natural and man-made activities on air pollution, and 3) alerting the administrator to the negative effect of NAAQS guidelines on public health, welfare, and socio-economic activities, as well as energy production.

In the REA, the health effects of air pollutants and their exposure are evaluated quantitatively. The resulting evaluations mostly offer information regarding observation and analysis of the health effects of air pollutants, as well as any corresponding uncertainty levels. More specifically, REA's methodology consists of air quality characterization, exposure assessment, and epi-based risk assessment. Methodology regarding uncertainty is also presented, so that results from the REA may be appropriately used in the PA.

\section{Policy Directions for Korean Air Quality Standards}

The system and procedures involved in reviewing NAAQS suggest possible procedural systematizations and evidence-establishing methodology for the establishment of Korean air quality standards.

First, systemizing the process of establishing air quality standards will eliminate obscurities in the current procedures for establishing atmospheric environmental standards, and it will increase reliability in the process of establishing environmental standards for the Framework Act on Environmental Policy, which forms the groundwork of the Clean Air Conservation Act, the Special Act on Seoul Metropolitan Air Quality Improvement, among others. Currently, the procedure for establishing air quality standards in South Korea is vague. Thus, the process should consist of comprehensive reviews, comprehensive scientific assessments, REA, PA, and rulemaking similar to the processes used by the EPA to establish NAAQS. Detailing these processes should be made possible by specifying the institutions and durations, as well as the procedures, content, results, and topics of consideration for each stage, with regard to establishing air quality standards.

Second, the methodology for collecting evidence for the establishment of air quality standards will allow the standards to be formed on the basis of evidence, for the purpose of improving the health of the residents of a nation, as in the Framework Act on Environmental Policy. Currently in South Korea, a diverse array of perspectives regarding the effect of air quality standards is being presented. Nonetheless, it has not yet been suggested how the health effects of air quality standards compare to the socio-economic effects of those standards. Thus, a Korean scientific advisory committee should be formed and maintained. The extensive, evidence-based review of air pollution by the scientific advisory committee should increase the professionalism, objectivity, and effectiveness of the review process, and suggest standards that take into account public health, environment management, integrated considerations of the environment and the economy, and the conservation and re-use of resources, so as to improve both the health and welfare of the people of South Korea.

\section{Tools for Korean Air Quality Standards}

\section{Health Effect Studies of Air Pollution in South Korea}

The HEI's PAPA project assists policymakers in setting regulations and interventions by supplying summaries of over 420 research papers concerning the Asian Continent via the PAPAScience Access on the Net. Among the papers published between 1980 and 2007, a total of 51 listed in the SCI address the health effects of air pollution in South Korea [10].

Most of these studies focused on Seoul and Incheon, and 26 of them were time-series studies evaluating the acute health effects of short-term exposure to air pollutants. The end-point health effects of air pollution exposure were evaluated by 22 studies in which mortality rates were the highest, with studies focusing on hospitalization involving respiratory devices, symptoms in the respiratory system, and lung functions also making up the majority. With regard to air pollution, over $50 \%$ of the studies were found to have assessed levels of $\mathrm{PM}_{10}, \mathrm{NO}_{x}, \mathrm{SO}_{2}, \mathrm{CO}, \mathrm{O}_{3}$ - general air pollutants in South Korea-while none were found to have investigated levels of $\mathrm{PM}_{2.5}$, which has been a recent problem in South Korea (Table 1).

\section{Quantification Methodology for Linking Policy}

Generally, calculating the health burden arising from environmental risk factors in a local community makes it possible for one to compare with health burdens arising from other risk factors, and it can help in policy-making with regard to air quality standards or pollution prevention and management. Toward that end, tools for assessing the relationship between air pollutant concentration and their health effects, as well as tools for calculating the local-community health burden and for perceiving, interpreting, and making decisions based on the local-community health burden, were selected and proposed.

First, the tool for assessing the relationship between air pollutant concentrations and health effects consists largely of two tests: an assessment of the acute health effects of short-term ex- 
Table 1. Characteristics of the 51 studies identified in the Public Health and Air Pollution in Asia-Science Access on the Net Asian literature review, 1980-2007

\begin{tabular}{|c|c|}
\hline Characteristic & Studies (n) \\
\hline \multicolumn{2}{|l|}{ Study design } \\
\hline Cross-sectional & 5 \\
\hline Time series & 26 \\
\hline Cohort & 3 \\
\hline Panel & 5 \\
\hline Case-control & 1 \\
\hline Case crossover & 7 \\
\hline Health impact & 1 \\
\hline Ecologic & 3 \\
\hline \multicolumn{2}{|l|}{ Health outcome } \\
\hline Death & 22 \\
\hline $\begin{array}{l}\text { Hospitalization (asthma, chronic obstructive } \\
\text { pulmonary disease, bronchitis) }\end{array}$ & 14 \\
\hline Hospitalization (cerebrovascular disease) & 2 \\
\hline Respiratory symptoms or lung function & 8 \\
\hline Adverse pregnancy outcomes & 4 \\
\hline Lung cancer & 1 \\
\hline Other & 2 \\
\hline \multicolumn{2}{|l|}{ Exposure } \\
\hline TSP & 18 \\
\hline $\mathrm{PM}_{10}$ & 27 \\
\hline $\mathrm{PM}_{2.5}$ & 0 \\
\hline PM (unspecified) & 1 \\
\hline $\mathrm{NO}_{\mathrm{x}}$ & 33 \\
\hline $\mathrm{SO}_{2}$ & 37 \\
\hline $\mathrm{CO}$ & 26 \\
\hline $\mathrm{O}_{3}$ & 35 \\
\hline $\mathrm{Pb}$ & 1 \\
\hline VOCs & 1 \\
\hline
\end{tabular}

Studies could have addressed more than one health outcome or exposure. Time series studies included episode studies.

posure and an assessment of the chronic health effects of longterm exposure. Health effect assessments of long-term exposure consist mainly of cohort studies, while the assessments of shortterm exposure consist mainly of time-series studies [11].

In cohort studies, it is important to identify cohorts with enough variations in their exposure to air pollutants, and to assess the differences in health effects due to different levels of long-term exposure of air pollutants in individuals of varying demographics. However, it is difficult to construct cohorts in which each individual is varied in air pollutant exposure. For this reason, cohort studies are commonly assessed via survival analysis [12].

Time-series studies evaluate the relationship between changes in air pollutant exposure levels and changes in the incidence rates of health effects over a short time period (generally daily time changes). These studies are also called ecological studies, as they assess the relationship between population-based exposure levels and health effects, rather than between individual units, as in cohort studies. However, while day-by-day population-based data are easy to collect, there is no way to control individual variances (smoking habits, age, gender, etc.) in a population. Time-series studies are analyzed most commonly by semiparametric Poisson regression, which is useful in controlling the interaction among various demographic factors [13].

Secondly, the tool for calculating the local-community health burden due to air pollutant exposure is associated with calculating environmental burdens of disease (EBD). EBD refers to the extent of disease burdens arising from environmental risk factors, and the Environmental Benefits Mapping and Analysis Program (BenMAP) is the tool most prominently employed by the EPA to calculate local-community health burdens and benefits due to reductions in air pollutant concentrations [14].

BenMAP calculates local-community health burdens or benefits due to air pollutants by taking into account the concentration-response function, which expresses the relationship between air pollutant exposure and health effects, and the health of a local community (or the prevalence of certain health effects) as well as the size of the population of a local community. More specifically, BenMAP constructs air pollutant exposure maps based on population and location; compares benefits of various air quality management policies; estimates the health effects of current air pollution levels and the expenses incurred by them; predicts health benefits or effects that may result from strengthening or easing air quality control; and analyzes the function of health and estimated economic values regarding environmental changes, as well as sensitivity of the input data.

Thirdly, the tool for perceiving, interpreting, and making decisions based on local-community health burden calculations entails systemically evaluating the uncertainty involved in all the calculations as a whole [15]. Generally, it is impossible to eliminate uncertainty, but it can still be managed and improved. It would be useful in policy-making for researchers and policymakers to identify how latent uncertainties can affect the evaluations of health burden due to air pollutants.

To assess uncertainties, there should first be a method for assessing various types of uncertainties altogether. Uncertainty specialists have proposed a three-dimensional uncertainty assessment, through which 1) the location of the uncertainty, 2) the level of uncertainty, and 3) the nature of the uncertainty can be examined [15]. The location of the uncertainty refers to the point at which uncertainty may exist in certain steps of an assessment, while the level of uncertainty refers to the level of one's knowledge on a scale of complete ignorance to full knowledge. The nature of the uncertainty is divided into epistemic uncertainty and variability uncertainty; the former means uncertainties that arise from incomplete knowledge on the part of 
Table 2. The example of uncertainty assessment using uncertainty matrix

\begin{tabular}{|c|c|c|c|c|c|c|}
\hline \multirow[b]{2}{*}{ Location } & & \multicolumn{3}{|c|}{ Level } & \multicolumn{2}{|c|}{ Nature } \\
\hline & & $\begin{array}{l}\text { Statistical } \\
\text { uncertainty }\end{array}$ & $\begin{array}{c}\text { Scenario } \\
\text { uncertainty }\end{array}$ & $\begin{array}{l}\text { Recognised } \\
\text { ignorance }\end{array}$ & $\begin{array}{l}\text { Epistemic } \\
\text { uncertainty }\end{array}$ & $\begin{array}{l}\text { Variability } \\
\text { uncertainty }\end{array}$ \\
\hline \multirow[t]{2}{*}{ Context } & Multiple ways of defining the PM & & & + & & + \\
\hline & A subset of adverse health effect & & & + & & + \\
\hline \multirow[t]{4}{*}{ Model } & Acute health impact vs. chronic health impact & + & & & + & \\
\hline & Shape of concentration response curve & & + & & + & \\
\hline & The effects of both PM and other correlated pollutants & + & & & + & \\
\hline & Relative risk in susceptible population & + & & & + & \\
\hline \multirow[t]{2}{*}{ Inputs } & Interpolating of exposure data (or measuring of exposure population) & + & & & + & \\
\hline & Measuring health data & + & & & + & \\
\hline
\end{tabular}

From Ha J, et al. Uncertainty and estimation of health burden from particulate matter in Seoul metropolitan region. J Korean Soc Atmos Environ 2013;29(3):275-286 [4]. The sign of + indicate whether the characterization is or not in the uncertainty matrix.

a researcher, and the latter means uncertainties that are due to inherent variability in the data.

Total uncertainty may be visually and qualitatively assessed via the uncertainty matrix. The uncertainty matrix functions similarly to a list of locations, levels, and natures of all applicable uncertainties. Table 2 shows an uncertainty matrix for the calculations concerning the mortality rate burden arising from being exposed to the fine dust in the Seoul metropolitan region.

\section{Conclusion}

Scientific studies and methodologies regarding the health effects of air pollution were found to play a significant role in establishing air quality standards. Nevertheless, the process of establishing legal standards should not overlook the politics of various other fields along with scientific evidence regarding the health effects of air pollution. As much as health effects should be considered in establishing air quality standards, the social value of other fields should be considered as well.

This paper also showed that the establishment of air quality standards may act as the most powerful means to establish atmospheric management policies in order to attain better public health and welfare, this being the ultimate goal of atmospheric management policies. Furthermore, air quality standards should systematically consider the effects of air pollution from a diverse range of perspectives. In particular, policy-makers should primarily consider the health effects of pollution on humans when establishing air quality standards by using diverse quantitative methodologies for this process. In summary, atmospheric management policies should be based on the health effects of minimal air pollutant exposure, procedures similar to those involved in establishing evidence-based public health policies. Establishing evidence-based policies may be defined as the process or efforts of policy-makers to make objective decisions on the basis of accessible evidence.
It may be ideal to establish air quality standards that can protect at-risk populations from being exposed to air pollution. However, this is realistically impossible. When air quality standards demand zero risk of health effects from being exposed to air pollution, certain social foundations, such as those regarding economic growth, may cease to exist. Establishing policies such as air quality standards requires one to strike an appropriate balance between what standards can be upheld and what standards should be upheld. Air quality standards should be established according to scientific evidence that confirms the extent of the health effects of air pollution on the people of a nation, in the context of a diverse array of perspectives, such as politics, economics, social ethics, etc.

\section{Acknowledgements}

This study was supported by a project called "development of integrated model for climate change impact and vulnerability assessment and strengthening the framework for model implementation" from the Korea Environment Institute, funded by the Eco-Innovation, Ministry of the Environment, Korea (no. 2014-56).

\section{Conflict of Interest}

The author has no conflicts of interest with material presented in this paper.

\section{References}

1. Prüss-Üstün A, Corvalán C; World Health Organization. Preventing disease through healthy environments: towards an estimate of the environmental burden of disease. Gemeva: World Health Organization; 2006, p. 9.

2. International Agency for Research on Cancer. Air pollution and cancer. Lyon: International Agency for Research on Cancer; 2013, 
p. 13.

3. World Health Organization. Burden of disease from ambient air pollution for 2012 [cited 2014 Sep 12]. Available from: http:// www.who.int/phe/health_topics/outdoorair/databases/AAP BoD_results_March2014.pdf.

4. Ha J, Moon N. Uncertainty and estimation of health burden from particulate matter in Seoul metropolitan region. J Korean Soc Atmos Environ 2013;29(3):275-286 (Korean).

5. Pekkanen J, Pearce N. Environmental epidemiology: challenges and opportunities. Environ Health Perspect 2001;109(1):1-5.

6. Corvalán C, Briggs DJ, Zielhuis G; World Health Organization. Decision-making in environmental health: from evidence to action [cited 2014 Sep 12]. Available from: http://apps.who.int/iris/bitstream/10665/42304/2/0419259406_part1.pdf?ua=1.

7. Ministry of Environment. The study of setting policy direction for risk management of air pollution. Seoul: Ministry of Environment; 2013, p. 155-159 (Korean).

8. US Environmental Protection Agency. Integrated review plan for the ozone national ambient air quality standards [cited 2014 Sep 12]. Available from: http://www.epa.gov/ttn/naaqs/standards/ ozone/data/2011_04_OzoneIRP.pdf.

9. Jang Y. The need of risk assessment and strategies for air quality. Korea Society for Atmospheric Environment 2012 Fall Conference; 2012 Oct 25; Gyeogsan. Seoul: Korea Society for Atmo- spheric Environment; 2012, p. 107-123 (Korean).

10. Health Effects Institute. Outdoor air pollution and health in the developing countries of Asia: a comprehensive review [cited 2014 Sep 12]. Available from: http://pubs.healtheffects.org/getfile. php?u=602.

11. Pope CA 3rd, Dockery DW. Health effects of fine particulate air pollution: lines that connect. J Air Waste Manag Assoc 2006; 56(6):709-742.

12. Pope CA 3rd, Burnett RT, Thun MJ, Calle EE, Krewski D, Ito K, et al. Lung cancer, cardiopulmonary mortality, and long-term exposure to fine particulate air pollution. JAMA 2002;287(9):11321141.

13. Bell ML, Davis DL. Reassessment of the lethal London fog of 1952: novel indicators of acute and chronic consequences of acute exposure to air pollution. Environ Health Perspect 2001;109 Suppl 3:389-394.

14. US Environmental Protection Agency. Environmental benefits mapping and analysis program (BenMAP) [cited 2014 Sep 12]. Available from: http://www.epa.gov/airquality/benmap/docs. html.

15. Walker WE, Harremoës P, Rotmans J, van der Sluijs JP, van Asselt, MA, Janssen P. et al. Defining uncertainty: a conceptual basis for uncertainty management in model-based decision support. Integr Assess 2003;4(1):5-17. 